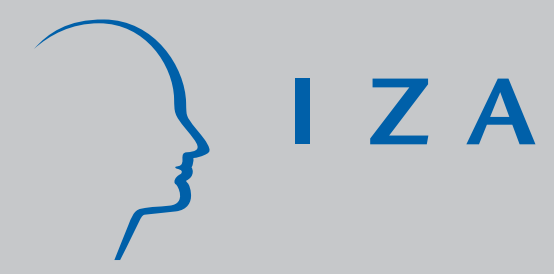

IZA DP No. 3236

Distributive J ustice and CEO Compensation

Guillermina J asso

Eva M. Meyersson Milgrom

December 2007 


\title{
Distributive Justice and CEO Compensation
}

\author{
Guillermina Jasso \\ New York University \\ and IZA \\ Eva M. Meyersson Milgrom \\ Stanford University
}

\author{
Discussion Paper No. 3236 \\ December 2007
}

\author{
IZA \\ P.O. Box 7240 \\ 53072 Bonn \\ Germany \\ Phone: +49-228-3894-0 \\ Fax: +49-228-3894-180 \\ E-mail: iza@iza.org
}

\begin{abstract}
Any opinions expressed here are those of the author(s) and not those of the institute. Research disseminated by IZA may include views on policy, but the institute itself takes no institutional policy positions.

The Institute for the Study of Labor (IZA) in Bonn is a local and virtual international research center and a place of communication between science, politics and business. IZA is an independent nonprofit company supported by Deutsche Post World Net. The center is associated with the University of Bonn and offers a stimulating research environment through its research networks, research support, and visitors and doctoral programs. IZA engages in (i) original and internationally competitive research in all fields of labor economics, (ii) development of policy concepts, and (iii) dissemination of research results and concepts to the interested public.
\end{abstract}

IZA Discussion Papers often represent preliminary work and are circulated to encourage discussion. Citation of such a paper should account for its provisional character. A revised version may be available directly from the author. 


\section{ABSTRACT}

\section{Distributive Justice and CEO Compensation ${ }^{*}$}

This paper develops a framework for studying individuals' ideas about what constitutes just compensation for chief executive officers (CEOs) and reports estimates of just CEO pay and the principles guiding ideas of justice. The sample consists of students pursuing a Master of Business Administration (MBA) degree in Sweden and the United States. The framework, based on justice theory and making use of Rossi's factorial survey method, enables assessment of ideas of fairness in CEO compensation, including (1) the just CEO compensation, in the eyes of each observer; (2) the principles of microjustice - observers' ideas about "who should get what" based on characteristics of CEOs and their firms; and (3) principles of macrojustice - ideas about the just level and dispersion in compensation across all CEOs. Our estimates yield the following main results: First, there is broad agreement on the median just CEO compensation but substantial inter-individual variation in the principles of microjustice and the other principles of macrojustice. Second, there is remarkable similarity in the distributions of the principles of microjustice and macrojustice across the MBA groups. Other important results include a pervasive gender attentiveness among MBA students and tolerance for large variability in CEO pay.

JEL Classification: D31, D6, D8, G30, I3, J16, J31, J33, M14, M52

Keywords: justice theory, fairness, CEO compensation, factorial survey method, MBA students, gender, inequality, Gini coefficient, Atkinson measure, Theil's inequality measures

Corresponding author:

Guillermina Jasso

Department of Sociology

New York University

295 Lafayette Street, 4th Floor

New York, NY 10012-9605

USA

E-mail: gj1@nyu.edu

\footnotetext{
* Authors listed in alphabetical order. Earlier versions of portions of this paper were presented at the Harvard-MIT Economic Sociology Workshop, Sloan School of Management, 2001; the Sociology Department Colloquium, Stanford University, 2003; the Management Colloquium, City University of Hong Kong, 2004; Symposium on Human Capital and Labour Markets, Zhejiang University, Hangzhou, China, 2004; the annual meeting of the Society for the Advancement of Socio-Economics, Washington, DC, 2004; the annual meeting of the American Sociological Association, San Francisco, California, 2004; the Economics Department at Stockholm University, 2005; and the biennial meeting of the International Society for Justice Research, Berlin, Germany, 2006. We are grateful to participants at those meetings and to colleagues at IZA for many valuable comments and suggestions. We also gratefully acknowledge the intellectual and financial support of the Bechtel Foundation, New York University, the Sloan School of Management at MIT, the Stockholm Institute of Business, and Stanford University. This paper is forthcoming in Acta Sociologica.
} 


\section{INTRODUCTION}

Recent increases in inequality in many countries of the world appear due to the increasing concentration of wealth at the top; and the increasing concentration of wealth at the top is in turn widely attributed to a new phenomenon in economic life, namely, very high-earning salaried workers, in particular, chief executive officers (Atkinson and Piketty 2006; Piketty and Saez 2006; Roine and Waldenström 2006).

Wealth and inequality awaken justice concerns. Substantial gaps between what people think is just and what they see around them generate judgments of injustice, setting in motion a train of negative consequences for individual and society (Bok 1993). Of course, ideas of justice may differ across individuals and across societies and their subgroups. Elites constitute one potentially important segment of the population, not only because of their decisionmaking activities but also because they may share a global common culture. Students pursuing a Master of Business Administration (MBA) degree are a special group of interest. The MBA students of today are the future CEOs, board members, entrepreneurs, and investors. Thus, their ideas about what is fair compensation, their views of the relevant factors in setting CEO compensation, and their tolerance or intolerance of inequality provide an important glimpse into the societal conversation on matters of compensation and inequality in the years to come. Moreover, to the extent that students come from all over the world, variability within university may reflect the diversity of their origins; across universities and countries, commonality may reflect the emerging global common culture while variability may reflect persistent distinctive ideas of justice and tolerance for inequality (Bok 1993; Kelley and Evans 1993; Master 2002; Söderström et al. 2003; Svallfors 1997; Wegener 1991).

In this paper we focus on CEO compensation as viewed by MBA students at two universities, one in Sweden, the other in the United States, asking three main questions: First, what are MBA students' ideas about fairness in CEO compensation - including not only ideas of the just amounts of pay but also ideas about the just returns to personal and firm characteristics (microjustice) and about the just level and dispersion in CEO pay (macrojustice)? Second, do 
MBA students within a university have a common view about what constitutes just CEO pay, just returns, and just level and dispersion? Third, are these ideas of justice similar across the two universities? ${ }^{1}$

To address these questions, we develop a framework which is based on justice theory and makes use of Rossi's factorial survey method, building on early studies of the justice of earnings (Jasso and Rossi 1977) and of elites (Berk and Rossi 1977; Jasso 1988). The framework links observers' ideas of justice, principles of microjustice, and principles of macrojustice, enabling estimation of these observer-specific quantities and assessment of the mix of agreements and disagreements across respondents.

The paper is organized as follows: In Section 2 we describe the framework and its theoretical and empirical background. The method used in the present study is developed in Section 3. Section 4 reports the results. A short discussion concludes the paper.

\section{JUSTICE JUDGMENTS OF CEO COMPENSATION: THEORETICAL AND EMPIRICAL BACKGROUND}

The work reported in this paper builds on and contributes to two research traditions, the first focused on large questions of increasing income inequality and attendant dynamics and the second on fairness concerns. Both converge on executive compensation and elites. The fairness literature suggests that two distinct kinds of principles operate to produce ideas of the just reward: (1) principles of microjustice - ideas about "who should get what" -- and (2) principles of macrojustice - ideas about what the overall distribution should look like (Arts et al. 1991; Berger et al. 1972; Brickman et al. 1981; Jasso 1983). That literature also suggests that ideas of justice are "in the eyes of the beholder" (Walster et al. 1976:4) and thus shaped by the observer's own characteristics, social location, and societal characteristics (Kelley and Evans 1993; Svallfors 1997; Verwiebe and Wegener 2000). Both literatures highlight the income domain

\footnotetext{
1 The words "justice" and "fairness" and their cognates are used interchangeably.
} 
(Arts et al. 1991; Atkinson and Piketty 2006; Bok 1993; Jasso and Rossi 1977; Kelley and Evans 1993; Piketty and Saez 2006). ${ }^{2}$

\subsection{Justice}

Justice theory identifies four main elements in justice processes. First, individuals and societies form ideas of justice; in the distributive-retributive domain these are ideas about what constitutes the just reward for specified rewardees, who can be self or other. Second, these ideas of justice may be used to help shape actual situations; for example, ideas of the just reward may play a part in salary decisions. Third, individuals judge the justice or injustice of actual situations, generating the justice evaluation; for example, they may judge that one person is overpaid and another underpaid and/or that the pay structure in a firm has unjustly too much inequality. Fourth, the justice evaluations become important determinants of further behaviors, such as lobbying for policies or candidates.

This paper is chiefly concerned with ideas of the just reward for CEOs. However, the method used to estimate the just reward is an indirect method that utilizes the justice evaluation function. Accordingly, we provide a brief background not only on the just reward but also on the justice evaluation and their associated functions.

Just Reward Function and the Principles of Microjustice. The just reward is the observer's idea of the just reward for a particular rewardee. It can be expressed as a function of characteristics of the rewardee and the rewardee's situation. This representation of the just reward function is owed to Berger, Zelditch, Anderson, and Cohen (1972), as shown in Jasso (1983), and is thus called the BZAC function. Of course, observers may disagree as to which worker/situational characteristics are relevant for just earnings or about the worth of such characteristics. Accordingly, we write a general just reward function:

$$
C=C(\boldsymbol{X}),
$$

where $C$ denotes the just reward and $\boldsymbol{X}$ denotes a vector of rewardee and situational

2 Succinct summary of the larger inequality framework is found in Piketty and Saez (2006) and of the justice framework in Jasso and Wegener (1997) and Jasso $(1999,2007)$. 
characteristics. To illustrate, in the earnings realm, $C$ represents just earnings, and the $\boldsymbol{X}$ vector contains both worker characteristics and situational characteristics, such as geographic region and industrial sector; some of the characteristics in the $\boldsymbol{X}$ vector may be salient to some observers and ignored by others.

The parameters of the BZAC just reward function (e.g., intercept and slope coefficients) represent just rates of return - for example, just rate of return to schooling and just rate of return to experience, as well as a just gender multiplier, and so on. Following Brickman et al. (1981), these quantities, which guide determination of the just reward in the observer's head, are collectively called the principles of microjustice.

Just Reward Distribution and the Principles of Macrojustice. When an observer forms ideas about the just reward for a set of rewardees, these ideas are also guided by distributional considerations, and these considerations are visible in the distribution formed by the set of just rewards. Following Brickman et al. (1981), parameters of the observer-specific just reward distribution - such as its mean and inequality - are called the principles of $\underline{\text { macrojustice. }}$

Justice Evaluation Function. The justice evaluation is the observer's assessment that a rewardee (self or other) is fairly or unfairly rewarded and, if unfairly rewarded, whether underrewarded or overrewarded, and to what degree. The justice evaluation, denoted $J$, arises from the comparison between an actual reward and a just reward. It is usually specified as the logarithm of the ratio of the actual reward, denoted $A$, to the just reward, denoted, as before, $C$ (Jasso 1978, 1999, 2006):

$$
J=\theta \ln \left(\frac{A}{C}\right)
$$

where $\theta$ denotes the signature constant. The sign of $\theta$ is called the framing coefficient, because it embodies the observer's framing of the reward as a good or as a bad (negative for a bad, positive for a good); and the absolute value of $\theta$ is called the expressiveness coefficient, because it transforms the observer's experience of justice into the expression thereof. The log-ratio form 
of the justice evaluation function has many appealing properties, and has been shown to be the only functional form which simultaneously satisfies two important conditions, scale invariance and additivity (Jasso 1990). ${ }^{3}$

Note that the justice evaluation serves to link the twin pillars of the justice literature: ideas of justice and reactions to injustice. Ideas of justice, as seen in equation (2), are one of the two arguments of the justice evaluation function; and reactions to injustice are the consequences of the justice evaluation. Thus, the justice evaluation connects the two foundational themes in the study of justice.

Two-Equation Model. The method we use for estimating the just rewards is based on a design in which each observer judges the justice or injustice of the actual reward associated with each rewardee in a set of rewardees (Jasso and Rossi 1977; Jasso 1990, 2007). Thus, the underlying model is a two-equation model consisting of the justice evaluation function and the just reward function (here written for a single observer):

$$
\begin{gathered}
j_{r}=\theta \ln a_{r}-\theta \ln c_{r} \\
\ln c_{r}=\pi_{0}+\sum_{k=1}^{K} \pi_{k} x_{k r}+\varepsilon_{r},
\end{gathered}
$$

where the justice evaluation, actual reward, just reward, and reward-relevant characteristics are denoted by lower-case letters, $r$ indexes the rewardee, $\pi$ denotes the parameters of the just reward function, and $\varepsilon$ is a classical error distributed independently with zero mean and constant variance (within the respondent-specific equation). ${ }^{4}$

As will be described in section 3.2, estimation of the observer-specific justice evaluation equation (the first equation in expression (3)), in which the just rewards are unobserved, yields an estimate of the signature constant $\boldsymbol{\theta}$, which is then used to calculate the true observer-

${ }^{3}$ For fuller discussion of properties of the justice evaluation function, see Jasso (2007).

${ }^{4}$ In the behavioral model in (3), the justice evaluation function appears in its theoretical form, i.e., without an error term. Below it will be transformed into an empirically estimable form, including an error term. 
specific/rewardee-specific just reward $c_{r}$. These estimated just rewards become the dependent variable in the observer-specific just reward equation (the second equation in expression (3)), which in turn yields estimates of the observer-specific principles of microjustice. Concomitantly, calculation of the mean and inequality measures in the observer-specific just reward distribution yields estimates of the observer-specific principles of macrojustice.

\subsection{Justice of CEO Compensation}

People make justice judgments about a wide variety of rewardees, including self and others, the latter both known and unknown to them. It is a commonplace - and much expressed in private conversations, letters to the editor of newspapers and periodicals, radio talk shows, and, now, web logs - that this or that athlete is overpaid and this or that actor is underpaid, etc.

CEOs are among the rewardees the justice of whose rewards is much evaluated. Several themes are discernible in public discussion of CEO compensation. First, the levels of CEO compensation are perceived as high; for example, the median CEO compensation in 2001 was \$7.1 million, and the distribution is highly positively skewed (Söderström et al. 2003). Second, compensation differentials - say, between a nurse and a CEO - appear to many to be disproportionate. Third, CEO compensation increased dramatically in the last two decades of the twentieth century - for example, in the United States averaging 9\% per year in the period 1980-1998 and outpacing not only compensation increases for rank and file workers but also the pay growth of 3.7\% per year among the wealthiest Americans (Hall and Liebman 1998; Piketty and Saez 2006). Fourth, CEOs appear to have lost the trust of the general population; the prevailing image is that of a CEO negotiating large compensation packages while fraudulently and criminally misrepresenting corporate performance for personal gain (Meyer 2003). Fifth, the system of corporate governance, in particular the set of checks and balances, has become a focus of criticism.

Of course, not all justice evaluations conclude with a verdict of overreward. For example, Crystal's (2002) analysis of executive compensation in companies with 2001 revenue of $\$ 8$ billion or more concluded that three of the CEOs are underpaid - including Warren Buffet 
of Berkshire Hathaway, whose business acumen is matched by his sense of ethics and fair play.

The scholarly literature on the justice of CEO compensation is anchored by two pioneering data collection efforts - the International Social Survey Programme (ISSP) and the International Justice Research Project (ISJP) - which have obtained information concerning what respondents regard as the just pay for "chairman of a large national corporation" and "chairman of a large company," respectively (Jasso 2007). However, these data do not lend themselves to estimating just pay for a broader range of CEOs - such as CEOs of small firms or multinational corporations. Moreover, they do not permit nuanced judgments that take into account personal characteristics of the CEO such as age or gender or other firm characteristics such as industry that is, they do not permit estimation of just reward functions and the principles of microjustice.

Accordingly, we use the factorial-survey justice design developed by Jasso and Rossi (1977) in order to achieve greater specificity. We specify a just compensation function that parallels the actual compensation functions discussed in the literature. The just compensation function includes characteristics of CEOs and of their firms which figure in both the actual compensation literature and in justice discussions, such characteristics as the age, gender, schooling, and experience of the CEO and the size and location of the firm (Baker and Hall 2004; Boxman et al. 1991; Conyon and Murphy 2000; Meyersson 1994; Murphy 1999; O'Reilly and O’Neill 2003; Rosen 1992). In the first application of the framework developed in this paper, we focus on CEOs newly hired as a CEO. ${ }^{5}$

\subsection{MBA Students and the Justice of CEO Compensation}

MBA students occupy a crossroads in the justice and CEO landscape. Like their fellows from high school and in common with the broader population, they judge the justice of CEO compensation. But unlike the broader population, they may have aspirations to become a CEO or take on other positions within the corporate world. And they have taken a significant step in the direction of casting their lot with business. Discerning their ideas of justice about CEO

5 Because the target CEOs in our study are newly hired as a CEO, we do not explicitly examine performance pay sensitivity, as is typical in the research literature (e.g., Murphy 1999). 
compensation provides a glimpse into the mindset of future entrepreneurs, CEOs, and board members. Note that to the extent that MBA students are drawn from around the world, they represent an international elite and thus their views may reflect both their national origins and their common global culture.

\section{METHOD: FACTORIAL SURVEY ANALYSIS AND JUSTICE JUDGMENTS OF CEO COMPENSATION}

To learn what MBA students regard as just compensation for CEOs and to estimate the justice principles guiding their judgments, we use Rossi's factorial survey method (Rossi 1979; Rossi and Anderson 1982; Rossi and Berk 1985; Jasso 2006), which has proved especially useful in studies of distributive justice, making it possible to obtain justice judgments about large sets of richly described fictitious rewardees (Berk and Rossi 1977; Jasso and Rossi 1977; Jasso 2007). The general factorial survey method provides several avenues for obtaining respondents' ideas of the just reward, including a direct method and (two versions of) an indirect method (Jasso 2007). The research reported here used the one-reward-per-rewardee version of the indirect method, in which a hypothetical actual reward is randomly attached to each rewardee, and respondents assess the fairness or unfairness of the actual rewards. The indirect method yields estimates of the just reward that are uncontaminated by socialization, rhetorical, political-correctness, or other disclosure mechanisms.

Briefly, we presented to respondents a set of 40 hypothetical CEOs, described in terms of own and firm characteristics, including a random compensation amount, and we asked the respondents to rate the justice or relative injustice of the hypothetical earnings. We used the obtained justice evaluations to estimate for each respondent the amount he or she thinks just for each of the hypothetical CEOs (the method involves a two-step procedure, described below). Next we used the estimated just compensation amounts to estimate for each respondent the principles of microjustice and macrojustice guiding his/her judgments. 


\subsection{Data Collection in the Factorial Survey Analysis of CEO Compensation}

The design of the data collection has three main ingredients: a sample of respondents, a population of hypothetical CEOs (the "vignettes") from which random samples are drawn and randomly assigned to respondents, and a rating task.

\subsubsection{Vignette Samples}

Vignette Characteristics. The vignettes include CEO and firm characteristics, plus a hypothetical amount of total direct compensation proposed for the CEO's first year as CEO of this firm. Total direct compensation consists of base salary, bonus, restricted stock and longterm incentives -- everything except stock option grants. MBA students would be familiar with these components of executive compensation.

Levels/values of vignette characteristics. Table 1 presents the vignette characteristics, together with their levels and values. As shown, age varies from 20 years to 70 years, schooling from completion of sixth grade to a doctoral degree, CEO compensation from fifty thousand to sixty million dollars. Of course, the real world is sufficiently diverse that most of the values in the vignettes have real-world counterparts. For example, in 2004, excluding those CEOs who at their request received total compensation of one dollar, CEO compensation in the top 500 U.S. companies ranged from $\$ 82,000$ to $\$ 230,554,000$ (www.forbes.com).

- Table 1 about here -

Firm headquarters is specified as being in one of three locations -- the United States, Europe, and Asia. The vignettes describe the CEO's firm as being in one of four major industries - manufacturing, finance and insurance, information, and wholesale trade.

Population of vignettes and drawing vignette samples. To obtain the random samples of vignettes to present to respondents, we followed these procedures: First, we fully crossed all characteristics except sex. The number of possible vignettes (Cartesian product) is: $11 \times 15 \times 16 \times 3 \times 4 \times 27 \times 27=23,094,720$. Second, we eliminated logically impossible combinations, following the specifications given in the note to Table 1; for example, age and experience as a CEO could not yield a CEO who became a CEO before age 16. Third, we drew 
two random samples, each of size 20 (called Decks 1 and 2). Fourth, each of the two random samples was used to generate two mirror-image samples with respect to sex, one describing men, the other women (e.g., Deck 1 gives rise to two decks, the all-female Deck 1a and the all-male Deck 1b). Finally, two superdecks of size 40 were constructed by taking the male version of one sample and the female version of the other sample, and vice-versa (e.g., Deck 1a and Deck $2 \mathrm{~b}$ form one superdeck).

Thus, each respondent received a pack with 40 vignettes. Though the 20 male and 20 female CEOs in each respondent's pack are not mirror images of each other, across all respondents the male and female CEOs are indeed mirror images of each other.

\subsubsection{Rating Task}

The respondent was asked to rate the justice or injustice of the hypothetical salary randomly attached to each CEO. The rating task used a number-matching technique developed by S. S. Stevens (1975), which gives respondents maximal freedom to map the subjective justice continuum onto numbers. The number zero is used to represent perfect justice, negative numbers to represent unjust underpayment, and positive numbers to represent unjust overpayment.

The usual protocol for factorial survey studies was followed (Jasso 2006, 2007). The instructions were read aloud, examples provided, questions answered. The instructions, besides describing the justice evaluation rating task, highlight the randomness of the attached hypothetical actual earnings and, to activate the full real-number line, make explicit mention of fractions and decimals; as well, to preserve independence of the ratings, the instructions say that respondents may change any of their ratings. Facsimiles of the instructions and of a vignette appear in Jasso (2006:412, 415).

The rating provided by the respondent for each rewardee is the justice evaluation described above (equation (2)) and produced by a comparison of the actual reward included in the vignette with the respondent's own idea of the just reward for the particular rewardee.

\subsubsection{Respondent Samples}

We selected two samples of MBA students, one from a Swedish institution, the other 
from a U.S. institution. The two institutions have similar curriculums, and the courses have similar content. Both institutions have a diverse student body drawing both from different domestic ethnicities and different origin countries. The proportion women is low to moderate in the two institutions, approximately $14 \%$ in the Swedish institution and $26 \%$ in the U.S. institution. In both institutions, we conducted the survey in the largest core course.

\subsection{Estimating the Just CEO Compensation}

As noted, we use the one-reward-per-rewardee version of the indirect method to estimate the amount of compensation that each respondent regards as just for each fictitious CEO.

The first step is to estimate the justice evaluation equation in the two-equation model (expression (3)), written, as before, for a single respondent:

$$
j_{r}=\theta \ln a_{r}-\theta \ln c_{r} .
$$

To begin, we transform the theoretical justice evaluation equation in (4), which has no error and in which the true just reward is unobserved, into an estimable empirical form, re-writing it as a simple regression equation with a stochastic term $u_{r}$,

$$
j_{r}=\alpha+\theta \ln a_{r}+u_{r}
$$

where $u_{r}$ obeys the classical assumptions. Because the respondent's ideas of the just reward for each fictitious rewardee are unobserved, they are absorbed into the regression intercept $\alpha$, which can be shown, by properties of linear regression, to amalgamate all the unobserved true just rewards:

$$
\alpha=-\theta E\left(\ln c_{r}\right) .
$$

This means that great care must be exercised in the estimation of (5) to guard against omittedvariables bias, which would arise if there is a correlation between the actual rewards and the unobserved just rewards. The steps taken to guard against such error are, first, ensure that the correlation of the actual reward and the reward-relevant characteristics (the CEO and firm characteristics) is zero in the vignette population, and, second, make clear to the respondents that the actual reward is random, stating this explicitly ("Each CEO has been randomly assigned a hypothetical total compensation for the first year."). 
Accordingly, estimation, for each respondent separately, of the empirical justice evaluation function in (5) yields an estimate of the signature constant $\theta$, from which the framing and expressiveness coefficients are immediately obtained.

Because in the factorial survey the descriptions of the rewardees are designed by the investigator and the actual reward is uncorrelated with the reward-relevant characteristics, the regressor $\ln \left(a_{r}\right)$ is fixed in the statistical sense and uncorrelated with the error, and, hence, the estimate of the signature constant $\theta$ has the desirable properties of unbiasedness and consistency.

To estimate the true just reward, we re-arrange the terms in the justice evaluation equation in expression (4), obtaining the formula for estimating the true just reward:

$$
\hat{c}_{r}=a_{r} \times \exp \left(-j_{r} / \hat{\theta}\right),
$$

where $\exp (\cdot)$ denotes the exponential function. Accordingly, when the justice evaluation equation is combined with the factorial survey design developed by Jasso and Rossi (1977), the factorial survey justice design provides the actual reward, the justice evaluation is obtained from the respondent, and the signature constant is estimated via statistical estimation of the equation (as shown above), leaving only one unknown - the just reward - which is easily solved for. The just rewards obtained by this method, being nonlinear transformations of an unbiased and consistent estimate -- of the signature constant -- lose unbiasedness but, by Slutsky's theorem, remain consistent. Thus, estimates obtained by the one-reward-per-rewardee version of the indirect method have the desirable properties that they are free of disclosure bias and that they are consistent but the undesirable property that they are biased. To mitigate bias and achieve the benefits of consistency, sample size is important. Though more research is needed to gauge optimal sample sizes, an initial rule is that vignettes number at least forty.

\subsection{Estimating the Principles of Microjustice and Macrojustice:}

\section{Just Reward Functions and Just Reward Distributions}

To estimate the respondent-specific just reward functions, we regress, separately for each respondent, the natural logarithm of just CEO compensation (estimated via formula (7)) on the CEO and firm characteristics. The obtained estimates, or transformations thereof, constitute 
estimates of the respondent-specific principles of microjustice.

To illustrate, the coefficient of schooling provides an estimate of the just earnings return to investment in an additional year of schooling. Age and experience are each represented by a quadratic form (i.e., by two regressors, such as age and age-squared), so that the just return to age or to experience is estimated by the two coefficients jointly. The exponential of the coefficient of the binary sex variable, measures the gender multiplier; women are coded " 1 " and thus the multiplier is applied to the earnings of females, so that subtracting one yields the tax (if negative) or bonus (if positive) on women's earnings, relative to the earnings of comparable men, in percentage points. The gender multiplier has a natural interpretation as the ratio of female to male earnings; a gender multiplier of .8 would indicate the view that the just earnings for a woman is $80 \%$ of the just earnings for a comparable man.

To test homogeneity of the respondent-specific just reward equations, we estimate three models and perform three tests contrasting them. ${ }^{6}$ Model I specifies a pooled equation in which all respondents have the same intercept and the same slopes. Model II retains common slopes but allows each respondent to have a unique intercept. Model III is the set of respondent-specific equations in which each respondent has both a unique intercept and unique slopes. Test 1 contrasts Model I with Model II. Test 2 contrasts Model II with Model III. Test 3 contrasts Model I with Model III.

The observer-specific just rewards form the just reward distribution. To estimate the principles of macrojustice, we calculate, for each respondent-specific distribution, the mean, median, and four measures of inequality.

\section{RESULTS}

\subsection{Preliminaries}

Of the 47 respondents in the Swedish study, 45 provided numerical nonconstant ratings,

6 The three models are labeled as in Johnston and DiNardo (1997:129-130). 
and of these, 43 provided information on gender (27 males and 16 females). Twenty-six of the 27 men and 13 of the 16 women rated all 40 vignettes; only 6 vignettes were left unrated, and the fewest number rated was 38. Estimation of the justice evaluation equations indicated that one male and one female each regarded earnings as a bad. ${ }^{7}$ These two respondents were dropped, leaving a usable Swedish sample of 26 males and 15 females.

In the U.S. sample, all 36 respondents provided numerical nonconstant ratings as well as gender information (30 males and 6 females). However, there are too few female respondents to constitute a female sample. Moreover, one of the men rated fewer than 30 vignettes and was eliminated, leaving a usable U.S. male sample of size 29. Twenty-four of the 29 men rated all 40 vignettes; one each rated 31,34, and 35 vignettes, and 2 rated 39 vignettes.

Accordingly, the data to be analyzed include three subsamples and enable a contrast between male MBA students in Sweden and in the United States and a second contrast between male and female MBA students in Sweden.

\subsection{Estimates of Just CEO Compensation}

Using the procedure described above, we estimated for each respondent the amount of compensation he/she thought just for each of the CEOs. The estimates are arrayed in a just reward matrix. To illustrate, Table 2 reports a portion of the just earnings matrix, showing the just earnings amounts for a quarter of the vignettes, namely ten each from two mirror-image decks. Our focus in this paper is on the rows of the matrix - namely, the respondent-specific just reward distributions to which we return in section 4.4 below. Of course, the rewardee-specific just reward distributions in the columns can also be usefully investigated

- Table 2 about here --

\subsection{Principles of Microjustice}

We begin by estimating the respondent-specific just reward equations. For each

${ }^{7}$ Factorial survey justice studies since the earliest days have found evidence of "contrarian" individuals, e.g., persons who regard earnings as a bad or time in prison as a goodexemplifying the old adage that one person's meat is another's poison. Deleting contrarians removes one source of variability, producing more conservative homogeneity tests. 
respondent, the forty logged just earnings amounts are regressed on the CEO and firm characteristics. Next, we carry out the homogeneity tests described in section 3.3, separately within each of the three samples. In all three samples, all three tests reject homogeneity at very high levels of statistical significance (beyond the .0001 level). We conclude that in forming their ideas of just compensation respondents differ in the weights they attach to CEO and firm characteristics.

As a brief illustration, consider the results for the Swedish male sample (Table 3); corresponding tables for the other two samples are available from the authors. The value of $R$ squared in the Model I equation, which constrains all respondents to have the same intercept and the same slopes, is a meager .113. Model II, which allows respondents to have unique intercepts, attains a value of $R$-squared of .346 , or triple that in Model I. Model III, which permits respondents to have their own intercepts and slopes, reaches an $R$-squared of .591, which almost doubles that in Model II and is over 5 times that in Model I.

\section{- Table 3 about here -}

Thus, the homogeneity tests yield the first important result: MBA students, even within country and within gender, do not agree with each other on the just bases for CEO compensation. As will be discussed, this may reflect the students' international origins and/or their independence of mind.

To assess the extent of agreements and disagreements, we examine the respondentspecific equation estimates. For each respondent, we have estimates of twelve coefficients, one intercept, and one value of $R$-squared. The thirteen parameter estimates satisfy the conditions for unbiasedness. We summarize the results in two ways. First, we present in panel A of Table 4 summary characteristics of all the coefficients plus $R$-squared. Second, we present graphs of the sample-specific quantile functions associated with several of the measures. The quantile function plots the value of a variable on its cumulative relative frequency, so that it is visually evident what proportion of respondents have values smaller than the plotted values. These plots permit immediate assessment of interrespondent disagreements and of similarity or dissimilarity 
of the distributions across the three samples.

- Table 4 about here --

Before discussing the estimates of the respondent-specific just CEO compensation equations, we inspect their values of $R$-squared (panel A of Table 4 and Figure 1). As shown, the values of $R$-squared range from .142 to .726. The means and medians in all three samples hover between .44 and .49 . These are substantial magnitudes, indicating that, although the respondents may disagree with each other on the importance associated with particular CEO and firm characteristics, they have coherent and orderly views concerning the effects of CEO and firm characteristics on just CEO compensation. As well, the values of $R$-squared indicate that the particular set of CEO and firm characteristics included in the vignettes are indeed relevant to the just pay for CEOs, in the respondents' eyes.

- Figure 1 about here -

Figure 1 tells an additional story. Notice how close together the three sample-specific distributions lie. Although there is considerable variability within sample, the three samples are very similar. These results suggest a common Weltanschauung among MBA students in both the Swedish and the U.S. institutions. ${ }^{8}$

The effect of CEO gender on just compensation is represented by the gender multiplier (Table 4, panel B, and Figure 2, panel A). As shown, the medians are in the range .84-.94, indicating that the median respondent regards as just an amount for women that is $84 \%$ to $94 \%$ that of otherwise identical male CEOs. Again, the three distributions are very similar to each other, parting company only at the extremes, especially the upper extreme. ${ }^{9}$

- Figure 2 about here -

8 Such a common Weltanschauung should not be too surprising, given that MBA students the world over have a similar curriculum. Moreover, asked about their major sources of business information, MBA students at both institutions mentioned the same three periodicals: The Wall Street Journal, The Financial Times, and The Economist. Further, both institutions draw students from all over the world. U.S. men.

${ }^{9}$ In the graph, the upper extreme values are interpolated for the Swedish women and the 
The respondent-specific estimates for the just rate of return to schooling (Table 4, panels A and B, Figure 2, panel B) indicate not only the large individual differences already expected but also somewhat less similarity across the three samples, especially in the bottom half of the distributions. The median just rate of return to schooling is substantially higher among the Swedish men (9.5\%) than among the Swedish women and U.S. men (5.5\% and 5.3\%, respectively). Swedish women also have the bottom third of the distribution with lower just returns than U.S. men. These results echo currents in the compensation literature, including the glory stories of entrepreneurial college dropouts, the view of schooling as a credentialing device, and the notion that schooling may be consumption as well as investment. ${ }^{10}$

The parabolas representing operation of experience as a CEO are concave downwards in a majority of each sample $(65 \%, 73 \%$, and 59\%, respectively, among Swedish men, Swedish women, and U.S. men). For these subsets, we show the quantile function of the sample-specific distributions of the years of experience at which just compensation peaks (Figure 2, panel C). ${ }^{11}$ Thus, these respondents judge as just a starting compensation for newly-hired CEOs that notices previous experience as a CEO but that peaks at a median experience of 6-9 years.

The firm location variables give rise to six possible orderings. The two orderings in which the United States is thought to provide larger just compensation characterize a plurality of respondents in all three samples, although the two orderings in which Asia has the larger coefficient is a strong contender among the U.S. male sample. Among the two Swedish samples, the two orderings with Asia at the top characterize the fewest number of respondents. These results suggest that in forming ideas of just compensation for CEOs, our respondents take into account the location of the firm headquarters but they disagree concerning which locations make

10 The quintessential example of entrepreneurial college dropouts is Bill Gates, founder of Microsoft. Another well-known example is Michael Dell, founder of Dell Computer (Dell 2003).

11 The plots omit a total of three values (from the graphs but not from the underlying distributions) - one each at the bottom and top in the Swedish male sample, and one at the top in the Swedish female sample. 
high earnings more appropriate.

The firm industry variables give rise to 24 possible orderings. All but one of the 24 possible orderings were used by at least one respondent. In each sample, the largest number of respondents associated with a single ordering are 4, 5, and 3 among Swedish men, Swedish women, and U.S. men, respectively.

The estimates for the effect of firm capitalization on just CEO compensation (Table 4, panel A, and Figure 2, panel D) show the now familiar pattern associated with the effects of quantitative characteristics - variability across individuals, similarity across samples. ${ }^{12}$ The medians lie in the range .14-.26. Thus, on average, respondents regard as just a CEO compensation that increases by approximately $.20 \%$ for a $1 \%$ increase in firm capitalization. In the vocabulary of economics, the estimated elasticity of CEO just compensation with respect to firm capitalization is in the range of .14 to .26 - a range consistent with Rosen's (1992) estimated range of .20 to .30 . Interestingly, the estimates in the two men's samples are even more similar to Rosen's estimates - a mean and median of the estimated elasticities of .23-.24 and .18-.26, respectively.

\subsection{Principles of Macrojustice}

Table 4 reports in panel $\mathrm{C}$ summary characteristics for the median and for the four inequality measures calculated on the respondent-specific just reward distributions. Graphs of the sample-specific quantile functions associated with the median and with the inequality measures are presented in Figures 3 and 4.

- Figures 3 and 4 about here -

The plots for the medians of the respondent-specific just reward distributions (Figure 3) indicate interrespondent similarity over most of the region. Moreover, the three plots are very similar, indicating similarity across the three samples. This pattern differs from the pattern

12 As suggested by inspection of the graphs and tabulated figures, there is one omitted value at the bottom of the range (among the U.S. men) and several at the top (one among Swedish men, three among Swedish women, and four among U.S. men). 
observed in the principles of microjustice of within-sample variability combined with crosssample similarity; here we observe similarity both within and across samples.

The graphs of the inequality measures (Table 4), however, display the same pattern as the principles of microjustice - great variability across respondents, great similarity across samples. Substantively, respondents regard as fair very high levels of inequality in CEO compensation. Most of the minimums are quite high - for example, the smallest values of the Gini index among Swedish men and women are .46 and .50, respectively, values higher than in the broader U.S. income distribution. The means and medians are in the range of .76-.78. At the upper extremes of the distributions, the magnitudes approach unity, the theoretical upper limit of the Gini index.

In the MLD, however, there is some dissimilarity across the three samples, albeit confined to the top half of the distribution. Swedish women appear tolerant of greater inequality (higher MLD).

In sum, the levels of inequality in CEO compensation that respondents regard as just are quite high.

\section{SUMMARY AND DISCUSSION}

In this paper we developed a framework for studying individuals' ideas about what constitutes just compensation for chief executive officers (CEOs), and we reported the results of the first application of the framework, assessing MBA students' ideas about just CEO pay, focusing on three samples: Swedish men, Swedish women, and U.S. men.

Our main results are: First, we obtained estimates of each respondent's ideas of the just pay for each of 40 fictitious CEOs, of each respondent's just reward equation and the principles of microjustice, and of each respondent's just reward distribution and the principles of macrojustice. These results make it possible to construct characterizations of respondents and CEOs, for example, that one respondent regards as just a return to schooling of 10 percent and another a return to schooling of 20 percent, that one respondent regards as just a Gini of .5 and another a Gini of .982, and so on. Second, within each of the three samples, there is substantial 
inter-individual variation in the principles of microjustice; that is, in forming ideas of just CEO pay, people differ in the weights they place on CEO and firm characteristics. Third, there is remarkable similarity in the distributions of the principles of microjustice across the three samples. Fourth, within each sample, there is broad agreement on the median just CEO compensation but substantial inter-individual variation in the inequality subset of the principles of macrojustice; that is, people differ in their tolerance for inequality. Fifth, there is remarkable similarity in the distributions of the principles of macrojustice across the three samples.

The estimates of the principles of justice provide an array of useful and suggestive results. For example, the distributions of observer-specific elasticity of just CEO compensation with respect to firm capitalization have medians in the range of .14-.26 - similar to the range of $.20-.35$ found by Rosen (1992). Further, the median respondents regard as just an amount of pay for women CEOs that is $84 \%$ to $94 \%$ that of otherwise identical male CEOs. With respect to variability in just CEO compensation, estimates of the principles of macrojustice indicate that the MBA students regard as just rather high levels of inequality in CEO compensation (e.g., median Gini index values of .76-.78), possibly dulling the senses to economic inequality in the larger population, where a Gini of .50 would be considered too high by most observers.

The findings of substantial inter-respondent differences on the principles of justice and of remarkable similarity in the distributions of principles of justice across the three samples jointly provide evidence for the existence of a global business culture, but one which, consistent with ideals of risk, innovation, and individualism, and possibly diverse origins, accommodates wide individual differences. Of course, the similarity we found between MBA students in Sweden and the United States may not extend to the general populations of the two countries. It is important to monitor views of CEO pay both inside and outside the business world, for a global business culture at odds with the general population would be a source of political tension both within and between national cultures.

The findings on the effects of CEO gender on ideas of just pay suggest substantial gender attentiveness on the part of MBA students. The factorial survey method makes it possible to 
retrieve ideas of fairness that respondents might otherwise be reluctant to express.

Whether gender attentiveness among MBA students persists, increases, or diminishes is a question for future research. Recent studies carried out in college samples in the United States (e.g., Jasso and Webster 1999) indicate that gender attentiveness is shifting. While U.S. college students increasingly assign equal just pay to otherwise identical male and female workers, they are not completely blind to gender, for the mechanisms by which they generate ideas of just earnings remain gender-attentive (for example, noticing gender in assigning just base pay or just returns to schooling). It will be important to monitor such shifts among MBA students. The factorial survey design is uniquely suited for this purpose.

There are several important directions for future research. We highlight three. Methodologically, an important task is to systematically contrast direct and indirect methods for measuring just pay, in order to understand the precise nature of the differences between them, to calibrate results across studies, and to help in research design. A second methodological task, building on Jasso (2006:4003-4007), is to examine sensitivity of indirect methods to alternate specifications of the justice evaluation function, assessing, for example, families of functions that share major properties with the logarithmic-ratio function.

Substantively, an important question for future research is to document ideas of just CEO pay among the general population as well as among other special target samples, such as workers, union members, regulators, legislators, business school faculty, faculty and students in other disciplines, and CEOs themselves, doing so not only in Sweden and the United States but also in additional countries around the world and repeating such studies periodically. Whether the world as a whole is becoming more similar in its views, whether, alternatively, pockets of the world's population are becoming internally more similar but polarized vis-a-vis each otherthese are vital questions for social, economic, and political development and for the well-being of the world's people. 


\section{REFERENCES}

Arts, Wil, Piet Hermkens, and Peter van Wijck. 1991. "Income and the Idea of Justice: Principles, Judgments, and Their Framing.” Journal of Economic Psychology 12:121140.

Atkinson, Anthony B., and Thomas Piketty. 2006. Top Incomes Over the Twentieth Century. Oxford: Oxford University Press.

Baker, George P., and Brian J. Hall. 2004. "CEO Incentives and Firm Size.” Journal of Labor Economics $22: 767-798$

Berger, Joseph, Morris Zelditch, Bo Anderson, and Bernard P. Cohen. 1972. "Structural Aspects of Distributive Justice: A Status-Value Formulation." Pp. 119-246 in Joseph Berger, Morris Zelditch, and Bo Anderson (eds.), Sociological Theories in Progress, Volume 2. Boston: Houghton Mifflin.

Berk, Richard A., and Peter H. Rossi. 1977. Prison Reform and State Elites . Cambridge, MA: Ballinger.

Bok, Derek. 1993. The Cost of Talent: How Executives and Professionals Are Paid and How It Affects America. New York: Free Press.

Boxman, Ed A. W., Paul M. De Graaf, and Hendrik D. Flap. 1991. "The Impact of Social and Human Capital on the Income Attainment of Dutch Managers." Social Networks 13:5173.

Brickman, Philip, R. Folger, E. Goode, and Y. Schul. 1981. "Micro and Macro Justice.” Pp. 173-202 in M. J. Lerner and S. C. Lerner (eds.), The Justice Motive in Social Behavior. New York: Plenum.

Conyon, Martin, and Kevin Murphy. 2000. "The Prince and the Pauper? CEO Pay in the United States and the United Kingdom.” The Economic Journal 110:640-671.

Crystal, Graef. 2002. "No Accounting for CEO Pay Gap." www.bloomberg.com .

Dell, Michael S. (with Patricia R. Olsen). 2003. "More Fun Than School.” The New York Times, Business Section, 9 March 2003. 
Hall, Brian J., and Jeffrey B. Liebman. 1998. “Are CEOs Really Paid Like Bureaucrats?” Quarterly Journal of Economics 113:653-691.

Jasso, Guillermina. 1978. "On the Justice of Earnings: A New Specification of the Justice Evaluation Function." American Journal of Sociology 83:1398-1419. . 1983. "Fairness of Individual Rewards and Fairness of the Reward Distribution: Specifying the Inconsistency between the Micro and Macro Principles of Justice." Social Psychology Quarterly 46:185-199.

. 1988. "Whom Shall We Welcome? Elite Judgments of the Criteria for the Selection of Immigrants." American Sociological Review 53:919-932.

. 1990. "Methods for the Theoretical and Empirical Analysis of Comparison Processes." Sociological Methodology 20:369-419. . 2006. "Factorial Survey Methods for Studying Beliefs and Judgments." Sociological Methods and Research 34:334-423.

. 2007. "Studying Justice: Measurement, Estimation, and Analysis of the Actual Reward and the Just Reward.” Pp. 225-253 in Kjell Törnblom and Riel Vermunt (eds.), Distributive and Procedural Justice: Research and Social Applications. London, UK: Ashgate. Manuscript available as IZA Discussion Paper No. 2592 at www.iza.org. , and Peter H. Rossi. 1977. "Distributive Justice and Earned Income." American Sociological Review 42:639-651. , and Murray Webster, Jr. 1999. "Assessing the Gender Gap in Just Earnings and Its Underlying Mechanisms." Social Psychology Quarterly 62:367-380. , and Bernd Wegener. 1997. "Methods for Empirical Justice Analysis: Part I. Framework, Models, and Quantities." Social Justice Research 10:393-430. Johnston, Jack, and John DiNardo. 1997. Econometric Methods. Fourth edition. New York, NY: McGraw-Hill.

Kelley, Jonathan, and M. D. R. Evans. 1993. "The Legitimation of Inequality: Occupational Earnings in Nine Countries.” American Journal of Sociology 99:75-125. 
Master, Melissa. 2002. "How Much Should A CEO Make?” Across the Board

(November/December). Website of The Conference Board (www.conference-board.org ).

McGeehan, Patrick. 2003. "Executive Pay: A Special Report.” The New York Times, 6 April 2003.

Meyer, Pearl. 2003. "From Halos to Horns: Demonizing the American CEO." Paper available at www.execpay.com .

Meyersson, Eva M. 1994. Kompensations Kontrakt I Börsnoterade Företag. Stockholm, Sweden: Almqvist \& Wiksell International.

Murphy, Kevin J. 1999. "Executive Compensation.” Handbook of Labor Economics 3B:24852562.

O’Reilly III, Charles A., and Olivia A. O’Neill. 2003. “Women’s Careers: The Impact of Sex and Gender Identity on Career Attainment." Unpublished paper.

Piketty, Thomas, and Emmanuel Saez. 2006. "The Evolution of Top Incomes: A Historical and International Perspective.” American Economic Review 96:200-205.

Roine, Jesper, and Daniel Waldenström. 2006. “The Evolution of Top Incomes in an Egalitarian Society: Sweden 1903-2004.” IFN Working Paper Number 667.

Rosen, Sherwin. 1992. "Contracts and the Market for Executives.” Pp. 181-211 in Lars Wein and Hans Wijkander (eds.), Contract Economics. Cambridge, MA, and Oxford, UK: Blackwell.

Rossi, Peter H. 1979. "Vignette Analysis: Uncovering the Normative Structure of Complex Judgments." Pp. 176-186 in Qualitative and Quantitative Social Research: Papers in

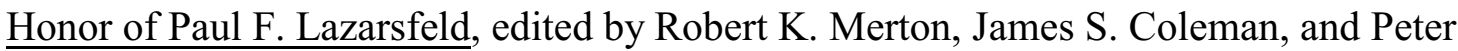
H. Rossi. New York: Free Press. , and Andy B. Anderson. 1982. "The Factorial Survey Approach: an Introduction." Pp. 15-67 in Measuring Social Judgments: the Factorial Survey Approach, edited by Peter H. Rossi and Steven L. Nock. Beverly Hills: Sage. 
Söderström, Hans Tson, Erik Berglöf, Bengt Holmström, Peter Högfeldt, and Eva M. Meyersson Milgrom. 2003. Corporate Governance and Structural Change: European Challenges. Stockholm, Sweden: SNS Förlag.

Stevens, S. S. 1975. Psychophysics: an Introduction to Its Perceptual, Neural, and Social Prospects. Edited by Geraldine Stevens. New York: Wiley.

Svallfors, Stefan. 1997. "Worlds of Welfare and Attitudes to Redistribution: A Comparison of Eight Western Nations." European Sociological Review 13:283-304.

Verwiebe, Roland, and Bernd Wegener. 2000. "Social Inequality and the Perceived Income Justice Gap.” Social Justice Research 13:123-149.

Wall Street Journal. 2003. "Special Report: Executive Pay.” April 14, 2003.

Walster, Elaine, Ellen Berscheid, and G. William Walster. 1976. "New Directions in Equity Research.” Pp. 1-42 in Leonard Berkowitz and Elaine Walster (eds.), Equity Theory: Toward a General Theory of Social Interaction. New York: Academic.

Wegener, Bernd. 1991. "Relative Deprivation and Social Mobility: Structural Constraints on Distributive Justice Judgements.” European Sociological Review 7:3-18. 
Table 1. Characteristics of the Fictitious CEOs Described in the Vignettes

\section{Age}

Eleven levels, in increments of five years, from 20 to 70 years.

2. Sex

(1) Male

(2) Female

\section{Years of Schooling Completed}

Fifteen levels, in increments of one year, from completion of sixth grade to a doctoral degree.

\section{Years as CEO}

Sixteen levels, in increments of one year, from 0 to 15 years.

\section{Firm Headquarters}

(1) United States

(2) Europe

(3) Asia

\section{Industry of This Firm}

(1) Manufacturing

(2) Finance and insurance

(3) Information

(4) Wholesale trade

\section{Size of Firm - Capitalization}

Twenty-seven levels, from $\$ 50$ million to $\$ 600$ billion. $[50 \mathrm{~m}, 75 \mathrm{~m}, 100 \mathrm{~m}, 125 \mathrm{~m}, 150 \mathrm{~m}, 175 \mathrm{~m}, 200 \mathrm{~m}, 250 \mathrm{~m}, 500 \mathrm{~m}, 600 \mathrm{~m}, 700 \mathrm{~m}, 800 \mathrm{~m}, 900 \mathrm{~m}$, $1 \mathrm{~b}, 5 \mathrm{~b}, 10 \mathrm{~b}, 15 \mathrm{~b}, 20 \mathrm{~b}, 25 \mathrm{~b}, 50 \mathrm{~b}, 75 \mathrm{~b}, 100 \mathrm{~b}, 200 \mathrm{~b}, 300 \mathrm{~b}, 400 \mathrm{~b}, 500 \mathrm{~b}, 600 \mathrm{~b}]$

8. CEO Total Compensation (salary, signing bonus, value of restricted stock, savings and thrift plans, and other benefits, but excluding options)

Twenty-seven levels, from $\$ 50$ thousand to $\$ 600$ million. [50t, 75t, 100t, 125t, 150t, 175t, 200t, 250t, 500t, 600t, 700t, 800t, 900t, $1 \mathrm{~m}, 5 \mathrm{~m}, 10 \mathrm{~m}, 15 \mathrm{~m}, 20 \mathrm{~m}, 25 \mathrm{~m}, 50 \mathrm{~m}, 75 \mathrm{~m}, 100 \mathrm{~m}, 200 \mathrm{~m}, 300 \mathrm{~m}, 400 \mathrm{~m}, 500 \mathrm{~m}, 600 \mathrm{~m}]$

Note: The population of fictitious CEOs (called "vignettes") consists of all the logically possible combinations of characteristics. Logically impossible combinations are deleted. These are defined as meeting one of the following conditions: (i) age minus schooling LT 5; (ii) age minus years as CEO LT 16; and (iii) capitalization/compensation LT 10. Random samples are drawn from the adjusted population for presentation to respondents. 
Table 2. Estimated CEO Just Earnings Matrix: Just Earnings (in Thousands of 2001\$) for CEOs, as Judged by MBA Students, Sweden 2001

\begin{tabular}{|c|c|c|c|c|c|c|c|c|c|c|c|}
\hline Resp & I & & & & & CEO & ID, Deck & $1 a$ & & & \\
\hline ID & i & 1 & 2 & 3 & 4 & 5 & 6 & 7 & 8 & 9 & 10 \\
\hline 1 & 1 & 1000 & 151523 & 18142 & 151523 & 175 & 11010 & 1783 & 19756 & 2469 & 390 \\
\hline 2 & 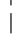 & 701 & 295 & 2349 & 63 & 222 & 1179 & 839 & 8516 & 1064 & 1863 \\
\hline 5 & i & 134 & 2785 & 449 & 1246 & 175 & 999 & 160 & 629 & 223 & 175 \\
\hline 7 & I & 104 & 2177 & 13 & 106 & 175 & 200 & 376 & 376 & 962 & 372 \\
\hline 9 & i & 537 & 1378 & 551 & 2567 & 401 & 5513 & 1211 & 11841 & 2241 & 3921 \\
\hline 11 & i & 2643 & 69 & 1872 & 483 & 175 & 731 & 800 & 103202 & 100 & 463 \\
\hline 15 & i & 1000 & 193 & 25 & 141 & 350 & 951 & 800 & 1599 & 283 & 350 \\
\hline 17 & i & 455 & 27385 & 120941 & 1170 & 36 & 22643 & 8512 & 199209 & 484 & 95846 \\
\hline 19 & | & 323 & 155 & 273 & 478 & 175 & 619 & 800 & 7652 & 956 & 541 \\
\hline 21 & i & 1000 & 3312 & 2277 & 549 & 175 & 13249 & 15992 & 8785 & 331 & 1056 \\
\hline 23 & 1 & 104 & 123 & 273 & 1182 & 175 & 776 & 638 & 12037 & 22639 & 275 \\
\hline 25 & 1 & 1000 & 90335 & 256 & 115 & 154 & 1606 & 985 & 1213 & 230 & 216 \\
\hline 27 & i & 9344 & 4365 & 2676 & 4365 & 1635 & 17461 & 18273 & 18273 & 8730 & 6250 \\
\hline 29 & i & 1000 & 234 & 2476 & 11018 & 3819 & 432 & 171 & 37736 & 22036 & 1767 \\
\hline 32 & I & 1000 & 75 & 16724 & 75 & 175 & 299 & 1196 & 44569 & 5571 & 1306 \\
\hline 34 & i & 1000 & 2697 & 9 & 2697 & 579 & 2189 & 5876 & 43154 & 149 & 389 \\
\hline 37 & i & 414 & 292 & 734 & 1703 & 504 & 1167 & 1620 & 9456 & 203 & 354 \\
\hline 39 & 1 & 10579 & 1359 & 574 & 1359 & 175 & 2116 & 800 & 34851 & 11192 & 175 \\
\hline 40 & i & 6 & 279 & 144 & 89 & 56 & 200 & 254 & 1419 & 3117 & 56 \\
\hline 42 & 1 & & & 3003 & 144 & 297 & 1665 & 471 & 1359 & 289 & 505 \\
\hline 43 & i & 7 & 994 & 171 & 135 & 39 & 200 & 295 & 295 & 100 & 175 \\
\hline
\end{tabular}

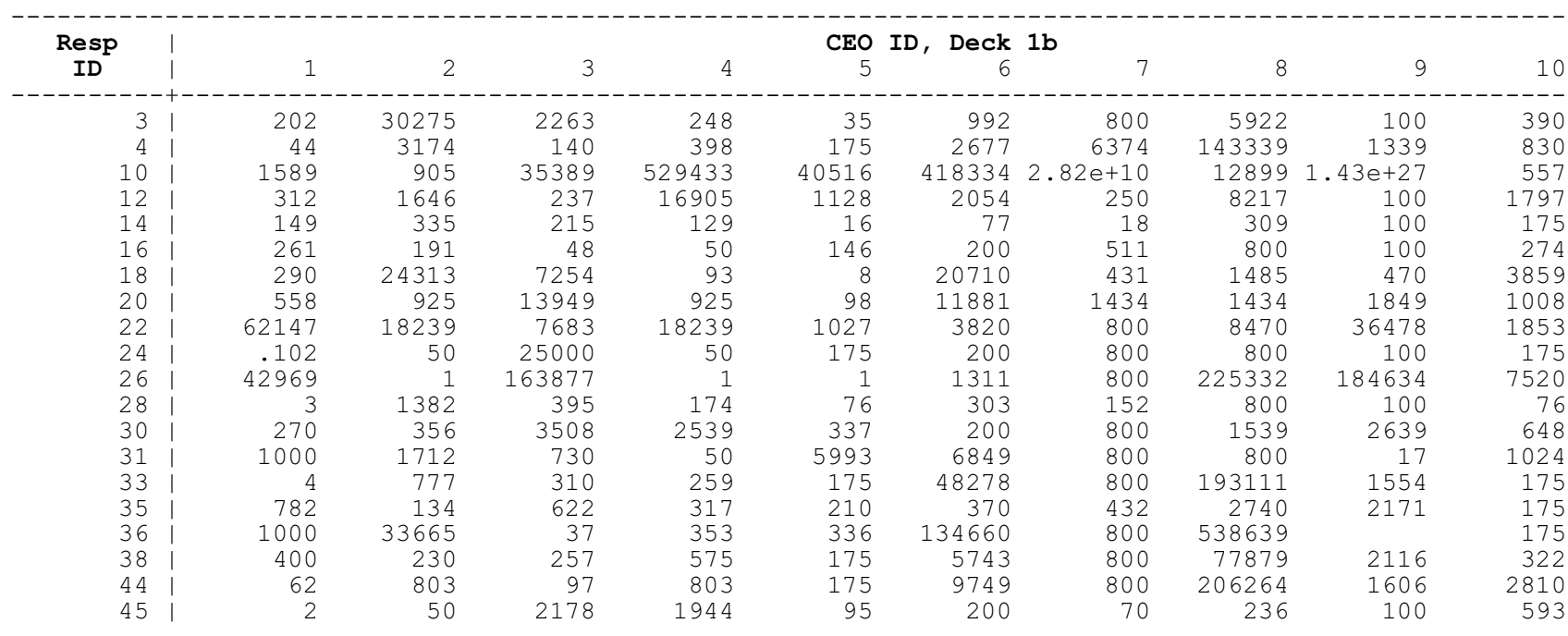

Notes: Each respondent rated two twenty-vignette decks, either Deck 1a and Deck $2 \mathrm{~b}$ or Deck $1 \mathrm{~b}$ and Deck 2a. The ten CEOs shown are from Decks $1 \mathrm{a}$ and $1 \mathrm{~b}$ (see text). CEOs with the same ID number are identical across these decks except for sex; the CEOs in Deck 1a are women and those in Deck $1 \mathrm{~b}$ are men. 
Table 3. Summary of Estimated CEO Just Earnings Functions and Hypothesis Tests:

Male MBA Students, Sweden 2001, 26 Respondents and 1039 Ratings

\begin{tabular}{ccc}
\hline \hline Model/Test & $R^{2}$ & $\begin{array}{c}F \text {-ratio } \\
(d f)\end{array}$ \\
\hline
\end{tabular}

Model I: Common intercept and common slopes (13 parameters)

$$
\ln c_{i r}=\beta_{0}+\Sigma \beta_{k} X_{k r}+\varepsilon_{i r} \quad 0.113 \quad 10.85
$$

Model II: Differential intercepts and common slopes (38 parameters)

$$
\ln c_{i r}=\beta_{0 i}+\Sigma \beta_{k} X_{k r}+\varepsilon_{i r}
$$

Model III: Differential intercepts and differential slopes (338 parameters)

$$
\ln c_{i r}=\beta_{0 i}+\Sigma \beta_{k i} X_{k r}+\varepsilon_{i r}
$$

Test of differential intercepts, conditional on common slopes: Model I vs. Model II

$$
\beta_{01}=\ldots=\beta_{026}
$$

Test of differential slopes, conditional on differential intercepts: Model II vs. Model III

$$
\boldsymbol{\beta}_{k 1}=\ldots=\boldsymbol{\beta}_{k 26}
$$

Test of differential just earnings functions: Model I vs. Model III

$$
B_{1}=\ldots=B_{26}
$$


Table 4. Summary Characteristics of Respondents' Model III Equations and Selected Principles of Microjustice and Macrojustice: MBA Students, Sweden (2001) and the United States (2002)

\begin{tabular}{|c|c|c|c|c|c|c|c|c|c|}
\hline & \multicolumn{3}{|c|}{ Swedish Men } & \multicolumn{3}{|c|}{ Swedish Women } & \multicolumn{3}{|c|}{ U.S. Men } \\
\hline & Mean & S.D. & Median & Mean & S.D. & Median & Mean & S.D. & Median \\
\hline \multicolumn{10}{|c|}{ A. Respondents' Model III Equations } \\
\hline Gender $(1=$ female $)$ & -.128 & .806 & -.0642 & .0256 & 1.55 & -.119 & -.0249 & 1.39 & -.180 \\
\hline Age & .157 & .177 & .167 & .0285 & .602 & .190 & .209 & .266 & .149 \\
\hline Age-squared & -.00154 & .00175 & -.00172 & -.000372 & .00564 & -.00200 & -.00208 & .00271 & -.00139 \\
\hline Years of schooling & .0777 & .0745 & .0947 & .0354 & .118 & .0549 & .0528 & .0878 & .0528 \\
\hline Years as CEO & .145 & .234 & .173 & .426 & .689 & .271 & .0355 & .518 & .0835 \\
\hline Years as CEO - squared & -.00628 & .0166 & -.00737 & -.0224 & .0478 & -.0132 & -.00154 & .0338 & -.00559 \\
\hline Firm in Europe & -.151 & .740 & -.134 & -.416 & .602 & -.539 & -.0547 & .661 & -.0668 \\
\hline Firm in Asia & -.37 & .839 & -.220 & -.428 & 1.18 & -.519 & .0179 & 1.15 & -.0470 \\
\hline Firm in finance/insurance & .119 & .690 & .0190 & .869 & .917 & .998 & -.146 & 1.34 & -.0132 \\
\hline Firm in information & -.00650 & 1.005 & .0130 & .640 & 1.16 & .682 & .235 & .777 & .174 \\
\hline Firm in wholesale trade & -.182 & .804 & -.228 & .665 & 1.70 & -.00462 & .251 & 1.02 & .0534 \\
\hline Firm capitalization (log mil) & .229 & .203 & .263 & .382 & .738 & .138 & .239 & .280 & .182 \\
\hline Constant & -.856 & 4.45 & -.749 & .175 & 11.8 & 1.12 & -1.34 & 6.57 & .414 \\
\hline$R^{2}$, just reward equation & .491 & .139 & .466 & .481 & .140 & .476 & .440 & .135 & .436 \\
\hline \multicolumn{10}{|l|}{ B. Principles of Microjustice } \\
\hline Just rate of return to school. & .0777 & .0745 & .0947 & .0354 & .118 & .0549 & .0528 & .0878 & .0528 \\
\hline Just male base wage (2001K\$) & 27.0 & 60.6 & .478 & $\rightarrow \infty$ & $\rightarrow \infty$ & 3.05 & 70.5 & 298.0 & 1.51 \\
\hline Just gender multiplier & 1.15 & .82 & .938 & 9.01 & 31.3 & .888 & 2.69 & 6.56 & .835 \\
\hline
\end{tabular}




\section{Principles of Macrojustice}

\begin{tabular}{lccccccccc} 
Just median CEO pay $(2001 \mathrm{~K})$ & 1270.39 & 1891.8 & 959.503 & 22871.2 & 83600.2 & 715.026 & 1738.23 & 2921.5 & 858.862 \\
Just Gini's ratio & .735 & .175 & .757 & .776 & .171 & .783 & .783 & .173 & .764 \\
Just Theil's ratio & 1.42 & 1.02 & 1.13 & 1.61 & 1.06 & 1.31 & 1.68 & 1.03 \\
Just Atkinson's ratio & .68 & .229 & .727 & .753 & .209 & .744 & .761 & .220 & .778 \\
Just MLD & 1.86 & 1.92 & 1.30 & 4.95 & 10.6 & 1.36 & 3.22 & 4.74 \\
\hline
\end{tabular}




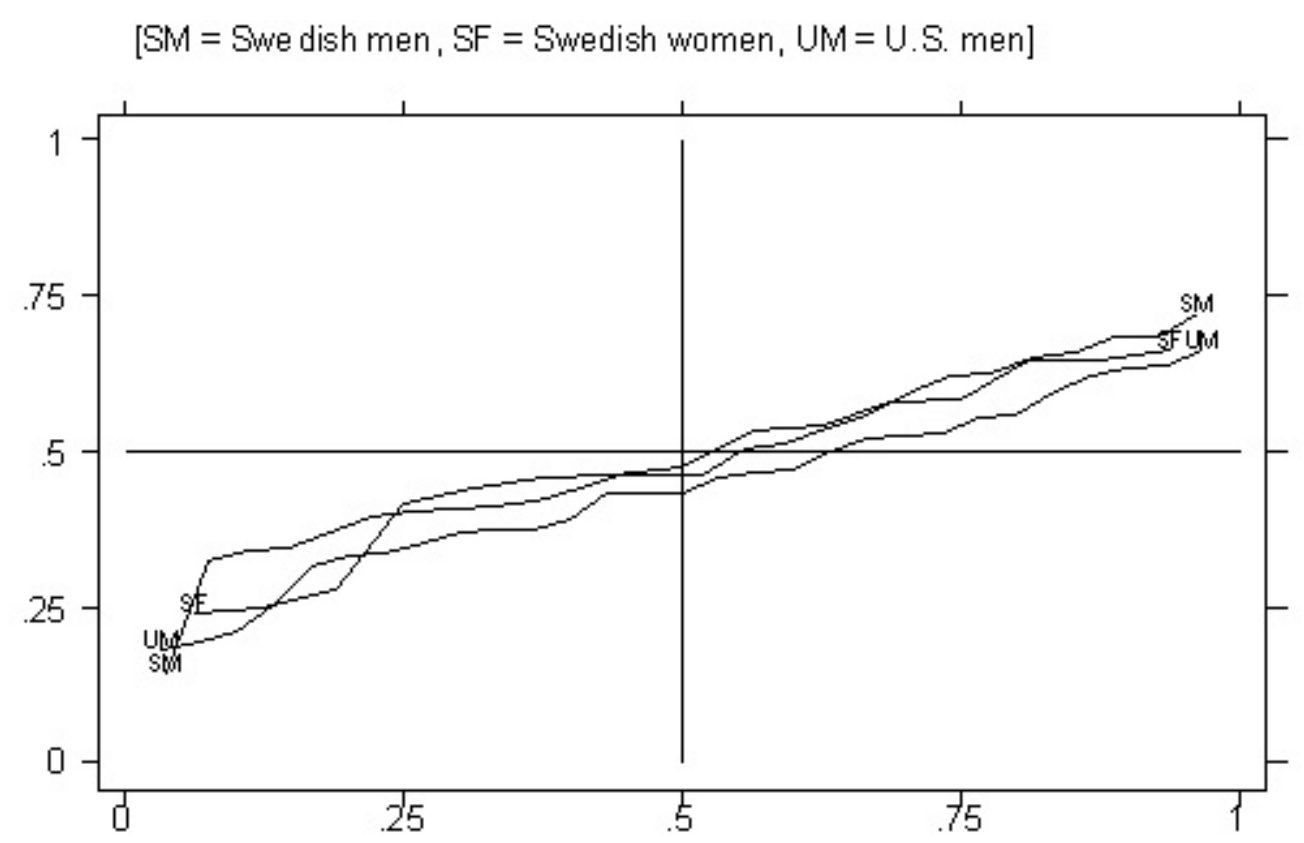

Figure 1. R-Squared in Respondent-Specific Just Earnings Equations 
[SM = Swedish men, SF = Swedish women, UM = U.S. men]
A. CEOGender
B. CEO Schooling
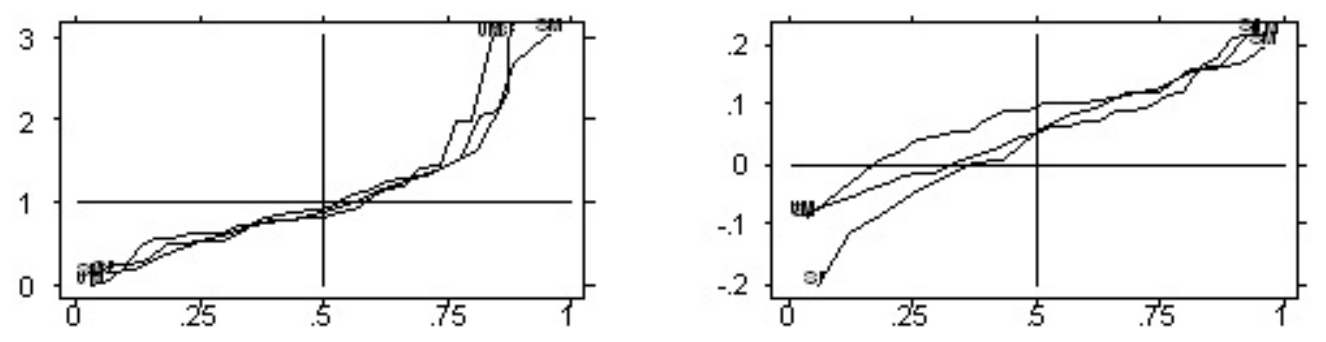

C. CEOE xperience at Peak Just Earnings

D. Log Fim Capitalization
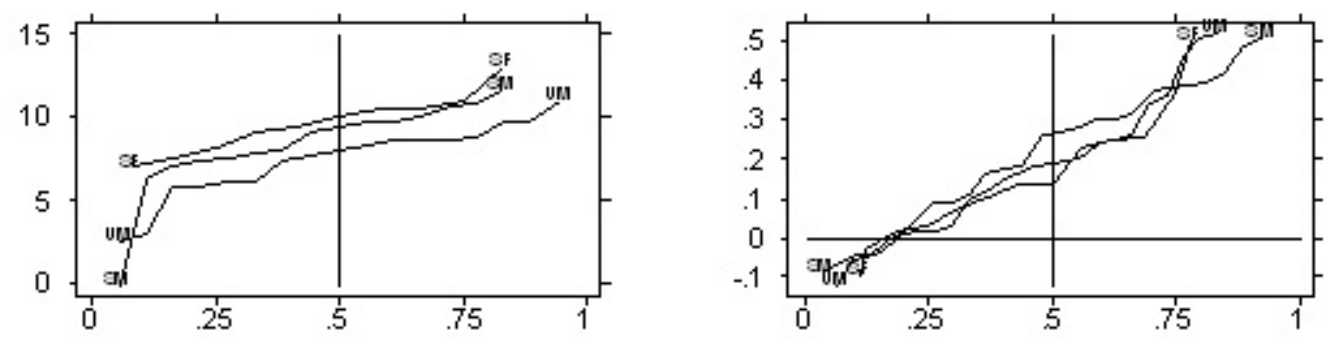

Figure 2. Respondent-Specific Principles of Microjustice 


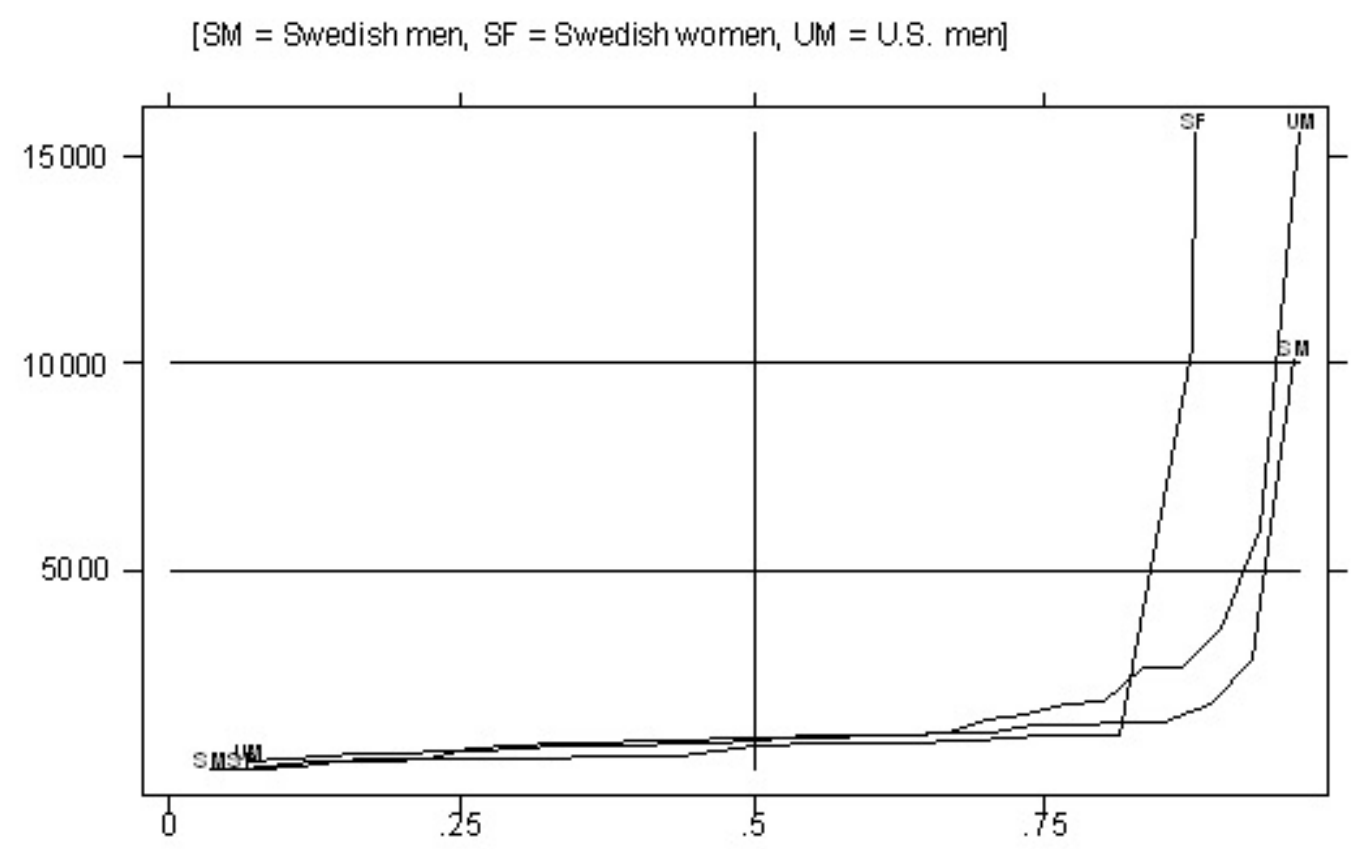

Figure 3. Principles of Macrojustice: Just Median CEO Pay 
[SM = Swedish men, $S F=S$ wedish women, UM = U.S. men]

A. Just Gini Index

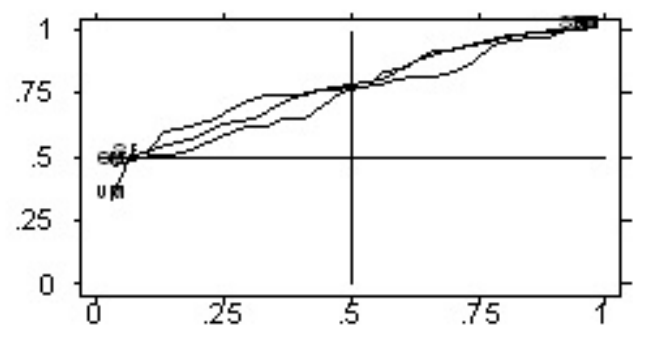

C. Just Theil Index

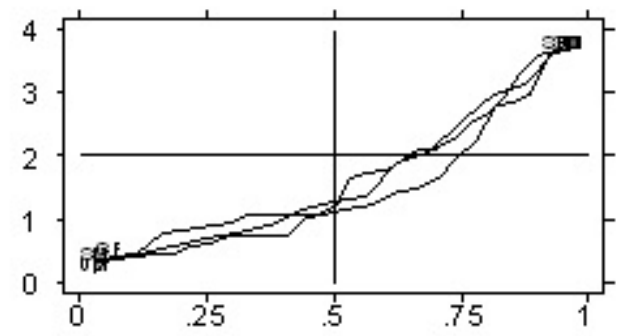

B. Just Atkinson Index

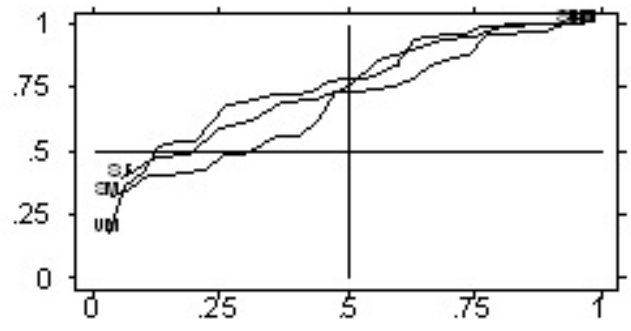

D. Just Mean Logarithm ic Deviation

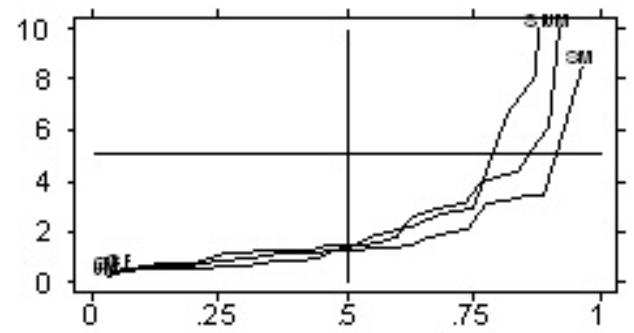

Figure 4. Respondent-Specific Principles of Macrojustice: Just Inequality 